\title{
25 Research Square \\ Characterization Of Microstructure And Selected Properties of SnSbCu Alloy After FSP
}

Joanna Hrabia-Wiśnios

AGH University of Science and Technology

Beata Leszczyńska-Madej ( $\sim$ bleszcz@agh.edu.pl)

AGH University of Science and Technology: Akademia Gorniczo-Hutnicza imienia Stanislawa Staszica w Krakowie https://orcid.org/0000-0003-0232-9080

Marcin Madej

AGH University of Science and Technology

Aleksandra Węglowska

Welding Institute

\section{Research Article}

Keywords: friction stir processing, $\mathrm{SnSbCu}$ alloy, microstructure, mechanical properties

Posted Date: May 26th, 2021

DOl: https://doi.org/10.21203/rs.3.rs-469608/v1

License: (c) (1) This work is licensed under a Creative Commons Attribution 4.0 International License. Read Full License

Version of Record: A version of this preprint was published at The International Journal of Advanced Manufacturing Technology on July 30th, 2021. See the published version at https://doi.org/10.1007/s00170-021-07781-1. 


\section{Abstract}

The paper presents the results of research on the microstructure and selected mechanical properties of the SnSbCu bearing alloy after friction stir processing (FSP). The Whorl tool was used for modification; the process was carried out using two rotational speeds of the tool: 280 and 450 RPM and a constant linear speed of $355 \mathrm{~mm} / \mathrm{min}$. Microstructure studies were performed employing the techniques of light microscopy and scanning electron microscopy along with analysis of the chemical composition of microareas. Additionally, the phase composition was investigated by means of the X-ray diffraction method and statistical analysis of the precipitates present in the investigated alloy. In addition, hardness, flexural strength and uniaxial compression tests were performed before and after FSP modification. It was proved that using FSP to modify the SnSbCu alloy promotes refinement and homogenization of the microstructure, as well as improvement of the flexural strength, whereas no changes in the hardness level were found.

\section{Introduction}

Alloys used to produce sliding bearing bushes should have appropriate mechanical properties, abrasion resistance and good corrosion resistance. Materials that exhibit such characteristics are tin-based bearing alloys. The microstructure of these alloys is multi-phase, most often in the three-phase form: $a, \beta$, $\eta$ or $a, \beta, \varepsilon$, where: $\alpha-$ an antimony and copper solution in tin, which is the soft and ductile matrix, $\beta$ angular SnSb crystals and $\eta$ - CuSn compound acicular precipitates [1, 2]. Due to the growing requirements for bearing alloys such as increasing loads/circumferential speeds and reducing machine sizes, the requirements for the strength properties are also rising. The data presented in scientific papers on tin Babbits indicate improvement in the properties of these alloys as a result of refinement and even distribution of the hard support phases in the tin-rich soft matrix. Sadykov et al. [3] investigated the effect of the cooling rate on the microstructure and properties of a tin Babbitt. They proved that reducing the particle size of the $\beta$ phase ( $\mathrm{SnSb}$ ) increases both the flow stress and the tensile strength. The authors of work [4] proved that the change in the morphology and size of the intermetallic phases obtained thanks to Babbitt heat treatment promotes improvement of the mechanical properties. This means that the dispersion of secondary phase particles seems to be an effective mechanism to strengthen tin alloys for sliding bearings. Cold hardening of bearing alloys is almost impossible due to their low recrystallization temperature. The results of the work by Sadykov [3] show that impacting plastic deformation in the rolling process at room temperature contributed to a significant increase in elongation in relation to the cast alloy (from 5 to $30 \%$ ), with a simultaneous drop in the strength properties. This clearly indicates the occurrence of changes in the structure of the studied alloy related to recrystallization.

Friction stir processing (FPS) is one of the innovative and promising methods of local modification of the microstructure of the surface layer [5,6]. A significant advantage of this processing technique is the possibility of obtaining a fully recrystallized microstructure, characterized by equiaxed, fine grains in the weld nugget, which is formed by intensive plastic deformation at an elevated temperature, not exceeding the melting point [7]. The fine-grained microstructure is responsible for the good mechanical and fatigue 
properties, and also improves plasticity [8-12]. The effect of improving the mechanical properties as a result of FSP modifications is well illustrated by the studies presented in $[13,14]$. The authors applied FSP treatment to A356 die casting aluminium alloys. The results of the research presented in work [13] showed an increase in refinement of the coarse Si needles and at the same time their uniform distribution with the increase in the rotational speed of the tool. A reduction in porosity in the cast material was also noted as a result of FSP treatment. In addition, it translated into an rise in the strength and plastic properties. FSP is successfully used in the automotive and aerospace industries, where materials are required to have greater resistance to wear, creep and fatigue. Thanks to continued research efforts and a better understanding of FSP, increasingly more applications of this method in the production, processing and synthesis of metal materials will be found.

Research on modification of the surface layer of bearing alloys using the FSP method is innovative. To date, only one work has been published in this field. It was proved, among others, that FSP modification of the SnSb11Cu6 bearing alloy with the Triflute tool promotes improvement of the tribological properties as a result of refinement of the hard phases present in the alloy [15]. This article focuses on the characteristics of the microstructure of the SnSbCu alloy containing, respectively, approx. 6 and $4 \mathrm{wt} \%$ antimony and copper after FSP modification using the Whorl tool. Particular attention was paid to the possibility of using the FSP method to increase the dispersion of secondary phase particles, which in turn may translate into improvement of the mechanical properties of this alloy.

\section{Material And Methodology}

The material to be studied was the tin-based casting bearing alloy $\mathrm{SnSbCu}$. The alloy was poured into cast iron moulds, then cooled in air. The chemical composition of the studied alloy is presented in Table 1.

Table 1

Chemical composition of investigated alloy, wt\%

\begin{tabular}{|llllll|}
\hline \multicolumn{2}{|l|}{ Name of alloy } & \multicolumn{4}{l|}{ Chemical composition, wt\% } \\
\hline Grade & Designation & $\mathrm{Sn}$ & $\mathrm{Pb}$ & $\mathrm{Sb}$ & $\mathrm{Cu}$ \\
\hline SnSb9Cu4 & B89 & 89.45 & 0.17 & 6.86 & 3.52 \\
\hline
\end{tabular}

FSP modification was carried out on a welding stand built on an FYF32JU2 vertical milling machine. The alloy was subjected to FSP using a tool consisting of a spiral shoulder and a Whorl pin - cone-shaped with a spiral-shaped thread (Fig. 1). The tool is made of high-speed steel HS 6-5-2 (SW7M). FSP was conducted using two rotational speeds of the tool: 280 and 450 RPM and a constant linear speed of 355 $\mathrm{mm} / \mathrm{min}$.

Examination of the microstructure of the samples was performed by means of light microscopy (OLYMPUS GX51 microscope) and scanning electron microscopy along with EDS analysis of the chemical composition in micro-areas (Hitachi SU 70 microscope, Tokyo, Japan). Additionally, the phase 
composition was analysed using a BRUKER X-ray diffractometer with a Co Ka $=0.179 \mathrm{~nm}(1.79 \AA)$ cobalt lamp. Quantitative analysis of the precipitates was performed in ImageJ Fiji on the basis of SEM micrographs (in the BSE detector observation mode). The quantitative research included analysis of the size of the precipitates and the nearest neighbour distance (NND). Hardness measurements were made using the Brinell method with a hardness tester by Innovatest; a tungsten carbide ball with a diameter of $2.5 \mathrm{~mm}$ and a load of $31.25 \mathrm{kG}$ were used. The average values of hardness and standard deviations were determined. The static uniaxial compression test was conducted at ambient temperature on a Zwick Roell Z020 testing machine. The compression test was carried out with a constant tool feed rate of $0.7 \mathrm{~mm} / \mathrm{s}$ and was stopped after achieving a permanent deformation of 45\%. Additionally, the Zwick Roell Z020 three-point flexural test was performed. The flexural test was conducted at room temperature and with a constant tool feed rate of $0.05 \mathrm{~mm} / \mathrm{s}$. In both the uniaxial compression and three-point flexural tests, the tests were performed on three samples from each variant.

\section{Results And Discussion}

\subsection{Microstructure characterization}

Observations of the microstructure of the cross-section of the zone after FSP modification depending on the rotational speed of the tool (Fig. 2) revealed a change in the structure and shape of the stir zone with an increase in the rotational speed of the tool. The FSP zone width and depth shrunk with increasing rotational speed. It is also worth drawing attention to the limitation of the depth of the impact of the tool shoulder with the increase in the rotational speed, which is related to the change in the amount of heat introduced to the stir area and its temperature. Increasing the rotational speed of the tool results in the fact that the material just below the surface of the tool reaches a higher temperature, and thus is able to bear smaller loads; while becoming more plastic it is "sheared" faster, and the depth of the shoulder impact is smaller. Previous studies show that the microstructure in the process zone depends on the process parameters (rotational speed of the tool, travel speed, pressure force), the type of material being processed and the shape of the tool [16-18]. The state of knowledge regarding the phenomena occurring during FSP is not yet fully known, which makes it difficult to select the optimal parameters for various alloys. In addition, observations of the microstructure after FSP modification revealed the presence of a nugget in the centre of the FSP zone, characterized by a lower degree of particle refinement, which is clearly noticeable when modifying with the lower tool rotational speed of 280 RPM (Fig. 2a) and disappears with increasing the rotational speed (Fig. 2b).

Arrangement of the material in the form of "onion rings" is visible, which is observed as a repeating pattern in the cross-section of the weld. They arise as a result of a rhythmic change in the size and distribution of the strengthening phase. The patterns repeat at intervals (seen in the cross-section) equal to the linear distance travelled by the tool during each rotation. The information presented in the literature indicates that it is related to oscillation of the tool rotation axis around its linear axis of motion [19]. Higher rotational speeds generate more heat, in addition, in the stir zone, layers with different material temperatures should be expected $[18,20]$, which leads to the formation of bands richer in precipitates 
(layers with a higher temperature) and bands poorer in secondary phases (layers with a lower temperature ) [18].

Figure $3 a$, b shows the microstructure of the studied alloy, while Fig. $3 c$ and $d$ presents the micrographs of the microstructure showing the stir zone depending on the rotational speed of the tool used. The microstructure of the alloy before modification consists of a few rhomboidal/cubic precipitates with stoichiometry corresponding to the SnSb phase and numerous needle-shaped and globular-shaped precipitates with stoichiometry corresponding to the $\mathrm{Cu}_{6} \mathrm{Sn}_{5}$ phase distributed on the background of a tinrich matrix (Figs. 3a, b), which is confirmed by the results of the EDS analysis (Fig. 4) and the X-ray phase analysis (Fig. 5). As a result of FSP modification, fine and equiaxed recrystallized grains of the tin-rich matrix (Fig. 3c, d) with a size of approx. 5-40 $\mu \mathrm{m}$ were formed in the microstructure. FSP generates a significant rise in temperature due to frictional forces, intense plastic deformation, and material flow caused by the movement of the tool, thus favouring dynamic recrystallization in the stir zone.

The EDS analysis of the chemical composition (Fig. 4) and XRD analysis of the phase composition (Fig. 5) showed no change in the phase composition of the alloy as a result of modification, while both the $\mathrm{SnSb}$ and $\mathrm{Cu}_{6} \mathrm{Sn}_{5}$ precipitates were significantly refined. The presented micrographs of the microstructure (Figs. 3, 4) show a change in the morphology of the $\mathrm{SnSb}$ and $\mathrm{Cu}_{6} \mathrm{Sn}_{5}$ phases present in the alloy. The shape of the $\mathrm{Cu}_{6} \mathrm{Sn}_{5}$ phase particles changed to more regular, close to globular, while the $\mathrm{SnSb}$ phase occurs in the form of very numerous, small globular particles, evenly distributed in the matrix - inside the grains and at the grain boundary (Fig. 3c, d, Fig. 4 - point 1). Lead is evenly distributed in the tin matrix, and also occurs in the form of small precipitates with a stoichiometry corresponding to the eutectic composition of $\mathrm{Sn}-\mathrm{Pb}$ (Fig. 4 - point 4).

One of the advantages of the FSP method is the possibility of obtaining a microstructure that changes in a gradient manner from the surface into the depth of the product to prevent defects, e.g. spalling. The transition zone between the stir zone and the thermo-mechanically affected zone and the area directly under the pin are determined mainly by adhesion, which is very important in the case of surface engineering [6]. Linear analysis of the chemical composition was performed to accurately characterize the transition areas from the stir zone towards the base material. The results of the linear analysis are shown in Figs. 6, 7. Additionally, in Fig. 6 the point corresponding to the clear transition boundary (point A) is marked with a dashed yellow line on the graph. Similarly, in Fig. 7 the area of significant refinement is between points $A$ and $B$ marked in the figure. The tests confirmed a significant increase in the refinement of the $\mathrm{Cu}_{6} \mathrm{Sn}_{5}$ and $\mathrm{SnSb}$ phase particles in the material stir zone after friction treatment on the advancing side (Fig. 6) and in the lower transition zone under the pin (Fig. 7). This is confirmed by the numerous peaks in the graphs corresponding to the composition of these phases.

In order to determine the influence of FSP on the microstructure of the studied alloy, including the process parameters, statistical analysis of the $\mathrm{SnSb}$ and $\mathrm{Cu}_{6} \mathrm{Sn}_{5}$ phases present in the microstructure was also performed. The results of the quantitative analysis including determination of the cross-sectional area of the particles and the nearest neighbour distance for the $\mathrm{Cu}_{6} \mathrm{Sn}_{5}$ phase are presented in Fig. 8, and for the 
SnSb phase particles in Fig. 9. The obtained results confirm the refinement of the microstructure as a result of FSP modification.

The particle size histogram of the $\mathrm{Cu}_{6} \mathrm{Sn}_{5}$ precipitates is characterized by an extremely asymmetric shape (Fig. 8a). A clear maximum in the histogram occurs for particle sizes under $25 \mu \mathrm{m}^{2}$, which in the case of the initial material account for about $76 \%$ of the studied population. On the other hand, as a result of FSP modification, this range includes approx. $81-90 \%$ of the analysed precipitates. The increase in rotational speed slightly influenced the refinement of the $\mathrm{Cu}_{6} \mathrm{Sn}_{5}$ phase. In addition, the results of NND measurements showed a shift in the population towards smaller distances between the precipitates for the material after FSP modification compared to the cast material (Fig. 8b). Moreover, the influence of rotational speed on the nearest neighbour distance was noticed. For the speed of 450 RPM, over $95 \%$ of the analysed population is below $10 \mu \mathrm{m}$, of which the nearest neighbour distance, less than $5 \mu \mathrm{m}$, is shown by approx. $50 \%$ of the studied precipitates. For comparison, for the initial material, only $32 \%$ of the population was in this range.

The results of measuring the size of the SnSb phase precipitates presented in Fig. 9a confirm its considerable refinement after FSP modification. There was an almost tenfold increase in the percentage of the smallest particles with a size below $5 \mu \mathrm{m}^{2}$ in the material after FSP treatment compared to the initial material. The use of FSP modification practically eliminates precipitates larger than $20 \mu \mathrm{m}^{2}$, while in the initial alloy these particles account for nearly $78 \%$ of the studied population of precipitates. The nearest neighbour distance measurement results also confirm a significant increase in particle refinement as a result of FSP modification. The NND histogram (Fig. 9b) indicated a significant shift towards shorter distances. Virtually the entire population of SnSb precipitates for the material after FSP modification is in the range below $15 \mu \mathrm{m}$, including $40-50 \%$ - below $5 \mu \mathrm{m}$, while in the case of the initial material no particle was recorded in the smallest distance interval; in contrast, $91 \%$ of the studied particles are at a distance greater than $15 \mu \mathrm{m}$.

\subsection{Mechanical properties}

The results of the Brinell hardness measurements for the material after FSP modification depending on the rotational speed of the tool are shown in Fig. 10. Modification of the SnSbCu alloy by FSP caused a slight fall in hardness in relation to the initial alloy $(20 \mathrm{HB})$, which is related to recrystallization of the alloy (Fig. 3). No significant influence of the tool rotational speed on the hardness result was noticed; the obtained hardness values remain at the level of 17-18 HB, of which the alloy after modification with the speed of 450 RPM has the highest hardness value (Fig. 10). At the same time, the 450 RPM modified alloy is characterized by the highest degree of refinement of hard particles of $\mathrm{Cu}_{6} \mathrm{Sn}_{5}$ precipitates and slightly larger SnSb precipitates compared to the material modified at the lower rotational speed (Fig. 9), which may justify the highest hardness for this material.

The results obtained in the static compression test depending on the state of the SnSbCu alloy (as cast, after FSP treatment with different speeds) are shown in Fig. 11. Table 3 summarizes the values of real stresses determined for all the considered variants of the alloy, which correspond to the actual strain 
amounting to 0.1 and 0.3 . The initial alloy is characterized by higher stress values in relation to the alloy after FSP modification, which can be explained by recrystallization of the tin-rich matrix. As a result of dynamic recrystallization of the material during FSP, the density of structural defects in the material is reduced. Therefore, there is a reduction in the strength properties of the material and improvement in its plastic properties.

The results of the flexural strength test (Fig. 12) showed its increase after FSP modification compared to the initial alloy, for which the flexural strength value was $214 \mathrm{MPa}$, and after the modification process, $307 \mathrm{MPa}$ (280 RPM) and $290 \mathrm{MPa}$ (450 RPM), respectively. The increase in flexural strength in the case of the alloy after FSP modification is caused by refinement of and a change in the morphology of the $\mathrm{Cu}_{6} \mathrm{Sn}_{5}$ phase particles to a more globular shape. It is worth noting that in the case of the samples after FSP treatment, cracks appeared on the advancing side, as shown in the photos of the samples after bending (Fig. 12). Due to the turbulent and highly dynamic flow, the stir zone is characterized by variable strains and strain rates around the rotating and simultaneously moving tool, generating the presence of various stress states (and cyclic forces) [19]. The tool rotation and travel directions are consistent on the advancing side, while on the retreating side they are opposite directions, with the result that the modified zone area on the advancing side is usually the hotter side of the process zone and has a higher stress level than the retreating side in the modified material $[20,21]$, at the same time it is more prone to cracking.

The fractures of the samples after bending have a transcrystalline malleable character with visible elevations and depressions resulting from plastic deformation within the plastic matrix, both for the initial alloy and the samples after FSP modification, and are brittle within the numerous intermetallic phases located in the alloy.

In the case of the cast material, numerous acicular precipitates of hard particles of $\mathrm{Cu}_{6} \mathrm{Sn}_{5}$ phases are visible, which undergo brittle fracture [3] much easier than the finer ones without sharp edges, formed after FSP modification (Fig. 13a). The sharp edges of the $\mathrm{Cu}_{6} \mathrm{Sn}_{5}$ acicular precipitates may favour the formation of cracks during the flexural test. After FSP modification, an increase in the share of the ductile nature of cracking was observed.

\section{Conclusions}

Based on the research, the following conclusions were drawn:

- The use of FSP modification to treat the surface of the SnSbCu bearing alloy causes a change in the morphology of the hard phases, including their strong refinement - confirmed by a rise in the share of the finest CuSn particles with an area under $25 \mu \mathrm{m}^{2}$ and SnSb with an area under $5 \mu \mathrm{m}^{2}$. In addition, FSP modification with the higher rotational speed of the tool results in greater refinement of the microstructure and its homogenization.

- The hardness tests revealed slight differences in hardness for individual sample variants. A slight change in the Brinell hardness of the studied material, as a result of FSP modification, is related to 
recrystallization in the stir zone, which results in a fall in Brinell hardness by approx. $10 \%$ compared to the cast material.

- The use of FSP treatment results in a reduction in the compressive stress. Additionally, it improves the flexural strength, which can be explained by the increase in the proportion of fine particles of the CuSn and $\mathrm{SnSb}$ intermetallic phases and the change in their morphology.

\section{Declarations}

Funding: This research was funded by the Polish State Committee for Scientific Research, grant number 16.16.180.006.

Conflict of interest: The authors declare that they have no conflict of interest.

Availability of data and material: The authors confirm that the data supporting the findings of this study are available within the article [and/or] its supplementary materials.

Code availability:Not applicable.

Author Contributions: Conceptualization, B.L.-M.; methodology, B.L.-M., M.M., J.H.-W. and A.W.; investigation, B.L.-M., M.M. and J.H.-W.; writing-original draft preparation, B.L.-M. and J.H.-W.; writingreview and editing, B.L.-M., J.H.-W., M.M., A.W.; visualization, B.L.-M. and J.H.-W. All authors have read and agreed to the published version of the manuscript.

\section{References}

1. Sotomi I, Tamura K, Goshima T (2010) Effect of amount of antimony on sliding wear resistance of white metal. Tribology International 43: 935-938. https://doi.org/10.1016/j.triboint.2009.12.047

2. Leszczyńska-Madej B, Madej M, Hrabia-Wiśnios J (2019) Effect of chemical composition on the microstructure and tribological properties of Sn-based alloys. Journal of Materials Engineering and Performance 28(7): 4065-4073. https://doi.org/10.1007/s11665-019- 04154-4

3. Sadykov FA, Barykin NP, Valeev ISh, Danilenko VN (2003) Influence of the Structural State on Mechanical Behavior of Tin Babbit. Journal of Materials Engineering and Performance 12(1): 29-36. https://doi.org/10.1361/105994903770343448

4. Leszczyńska-Madej B, Madej M (2013) Effect of the heat treatment on the microstructure and properties of tin Babbitt. Kovove Mater. 51:1-10. DOI: 10.4149/km 20132101

5. Mishra RS, Mahoney MW, McFadden SX, Mara NA, Mukherjee AK (2000) High strain rate superplasticity in a friction stir processed 7075 Al alloy. Scripta Mater. 42(2): 163-168. https://doi.org/10.1016/S1359-6462(99)00329-2

6. Miranda RM, Gandra JP, Luisa PV, Santos QTG (2014) Friction stir processing. In: Surface Modification by Solid State Processing, Woodhead Publishing, pp. 73-111 
7. Padhy GK, Wu CS, Gao S (2018) Friction stir based welding and processing technologies - processes, parameters, microstructures and applications: A review. Journal of Materials Science \& Technology 34: 1-38. https://doi.org/10.1016/j.jmst.2017.11.029

8. Sharma SR, Ma ZY, Mishra RS (2004) Effect of friction stir processing on fatigue behavior of A356 alloy. Scripta Materialia 51/3: 237-241. https://doi.org/10.1016/j.scriptamat.2004.04.014

9. Ma ZY, Sharma SR, Mishra RS (2006) Effect of multiple-pass friction stir processing on microstructure and tensile properties of a cast aluminum-silicon alloy. Scripta Materialia 54: 16231626. https://doi.org/10.1016/j.scriptamat.2006.01.010

10. McNelley TR (2010) Friction stir processing: refining microstructures and improving properties. Revista de Metalurgia 46: 149-156. http://dx.doi.org/10.3989/revmetalmadrid.19XIIPMS

11. Mishra RS, Ma ZY (2005) Friction stir welding and processing. Materials Science and Engineering $50:$ 1-78. https://doi.org/10.1016/j.mser.2005.07.001

12. Mahoney MW, Fuller CB, Miles MP, Bingel WH (2005) Thick plate bending of friction stir processed aluminum alloys. Proceeding of Friction Stir Welding and Processing III, San Francisco, pp.131-137.

13. Ma ZY, Sharma SR, Mishra RS, Mahoney MW (2003) Microstructural modification of cast aluminium alloys via friction stir processing. Materials Science Forum 426 - 432: $2891-2896$. https://doi.org/10.4028/www.scientific.net/MSF.426-432.2891

14. Kumar H, Prasad R, Kumar P, Tewari SP, Singh JK (2020) Mechanical and tribological characterization of industrial wastes reinforced aluminum alloy composites fabricated via friction stir processing. Journal of Alloys and Compounds 831: 154832. https://doi.org/10.1016/j.jallcom.2020.154832

15. Leszczyńska-Madej B, Madej M, Hrabia-Wiśnios J, Węglowska A (2020) Effects of the Processing Parameters of Friction Stir Processing on the Microstructure, Hardness and Tribological Properties of SnSbCu Bearing Alloy. Materials 13: 5826. https://doi:10.3390/ma13245826

16. Węglowski MS (2018) Review Friction stir processing - State of the art. Archives of Civil and Mechanical Engineering 18: 114 - 129. https://doi.org/10.1016/j.acme.2017.06.002

17. Zhang YN, Cao X, Larose S, Wanjara P (2012) Review of tools for friction stir welding and processing. Canadian Metallurgical Quarterly 51/3: 250-261. https://doi.org/10.1179/1879139512Y.0000000015

18. Hamilton C, Kopyściański M, Senkov O, Dymek S (2013) Material Flow Model of Friction Stir Welding Applied to Sc-Modified Aluminum Alloys. Metallurgical and Materials Transactions A, A Coupled Thermal 44a: 1730-1740. https://doi.org/10.1007/s11661-012-1512-y

19. Mishra RS, De PS, Kumar N (2014) Fundamentals of the Friction Stir Process. In: Friction Stir Welding and Processing, Science and Engineering, Springer International Publishing Switzerland, pp. 13-58

20. Hamilton C, Węglowski MS, Dymek S (2015) A Simulation of Friction-Stir Processing for Temperature and Material Flow. Metallurgical and Materials Transactions B 46: 1409-1418. https://doi.org/10.1007/s11663-015-0340-z 
21. Węglowski MS, Sedek P, Hamilton C (2016) Experimental analysis of residual stress in friction stir processed cast AlSi9Mg aluminium alloy. Key Engineering Materials 682: 18-23. https://doi.org/10.4028/www.scientific.net/KEM.682.18

\section{Figures}

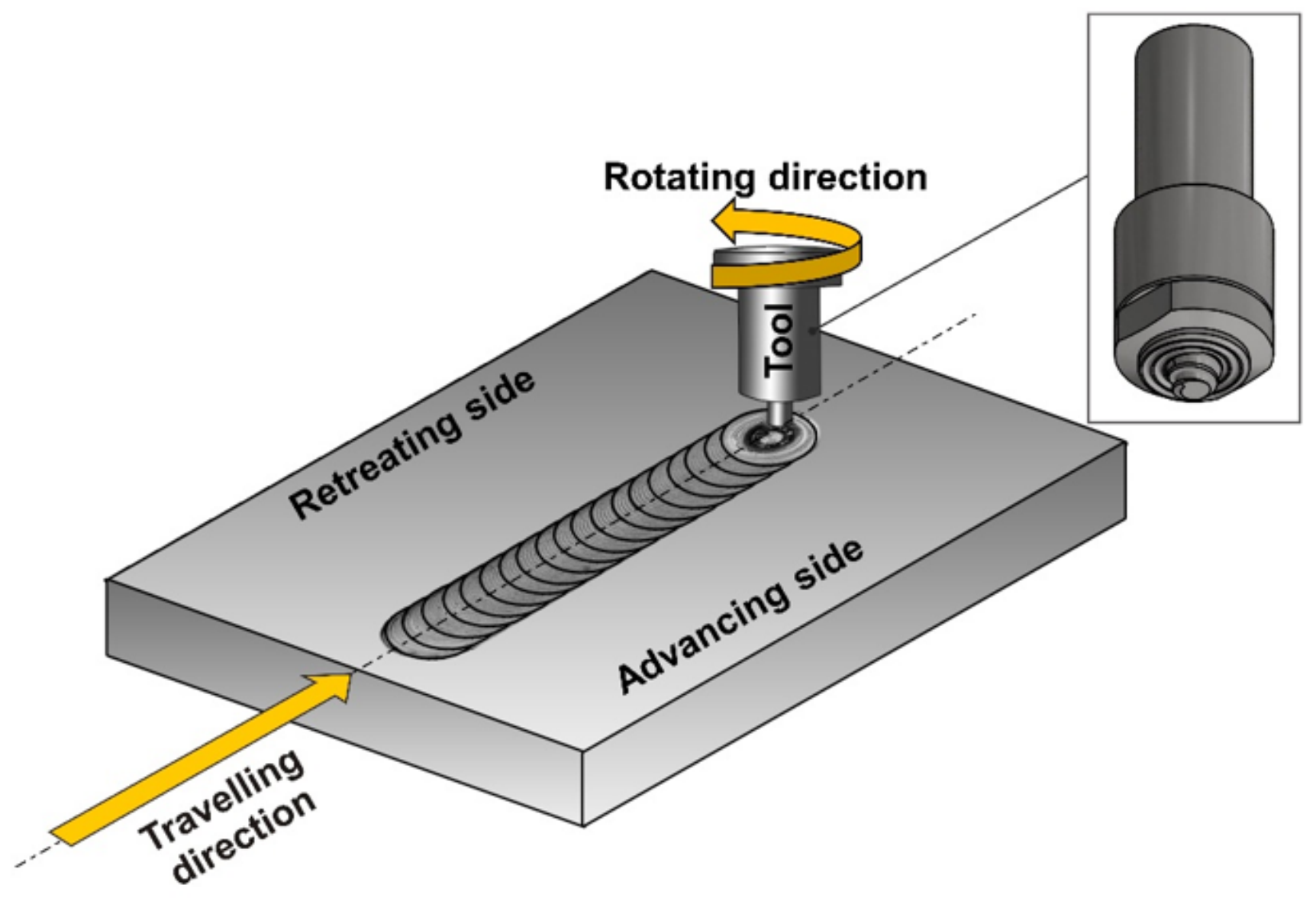

Figure 1

Diagram of FSP modification of surface layer; figure also shows diagram of Whorl tool 

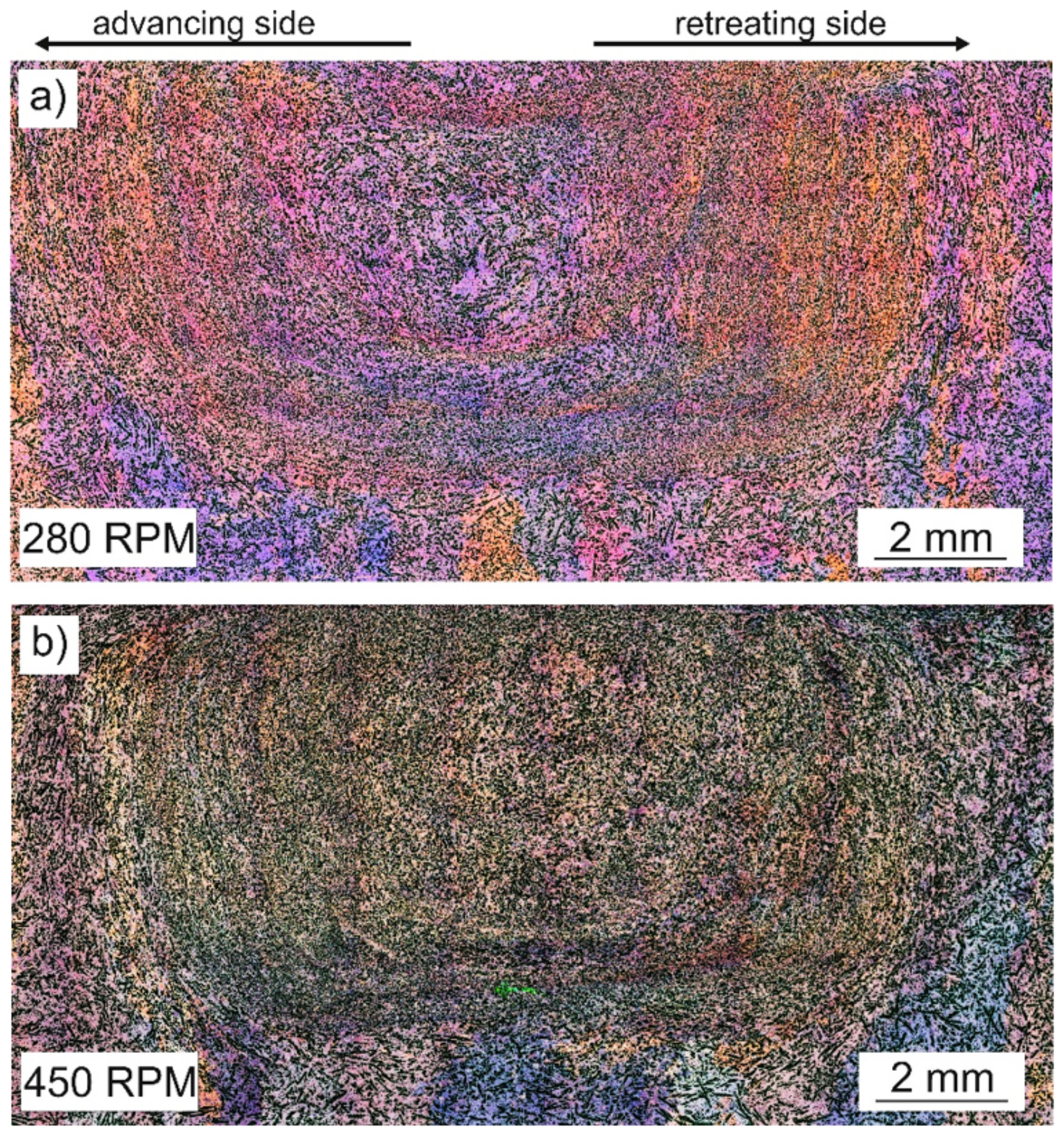

Figure 2

Microstructure of SnSb9Cu4 alloy after FSP with visible unmodified area (cross-section through FSP zone) depending on tool rotational speed: a) 280 RPM, b) 450 RPM; LM 


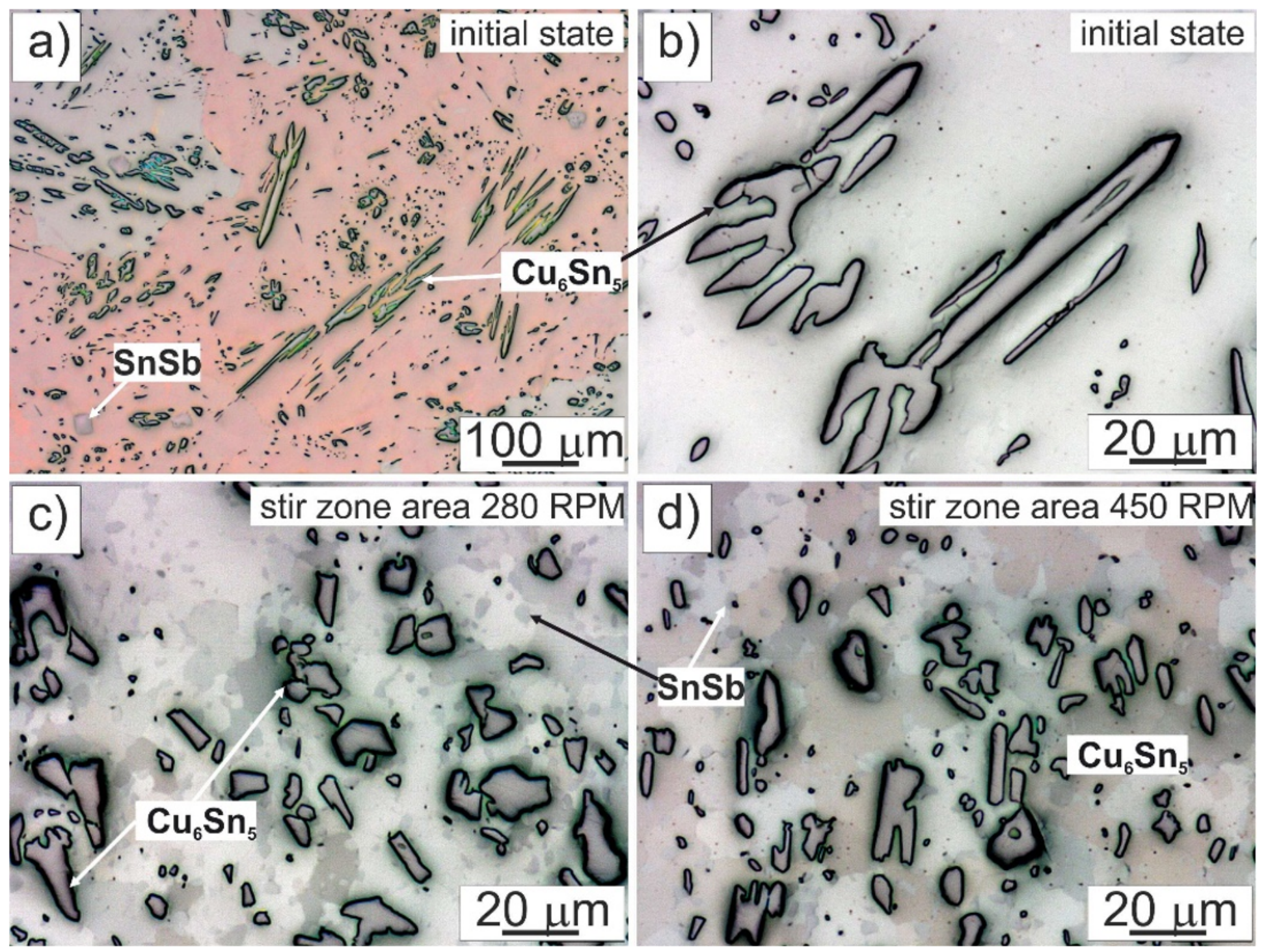

Figure 3

Microstructure of SnSbCu alloy: a, b) an initial state after casting, c) stir zone area 280 RPM, c) stir zone area 450 RPM, LM 


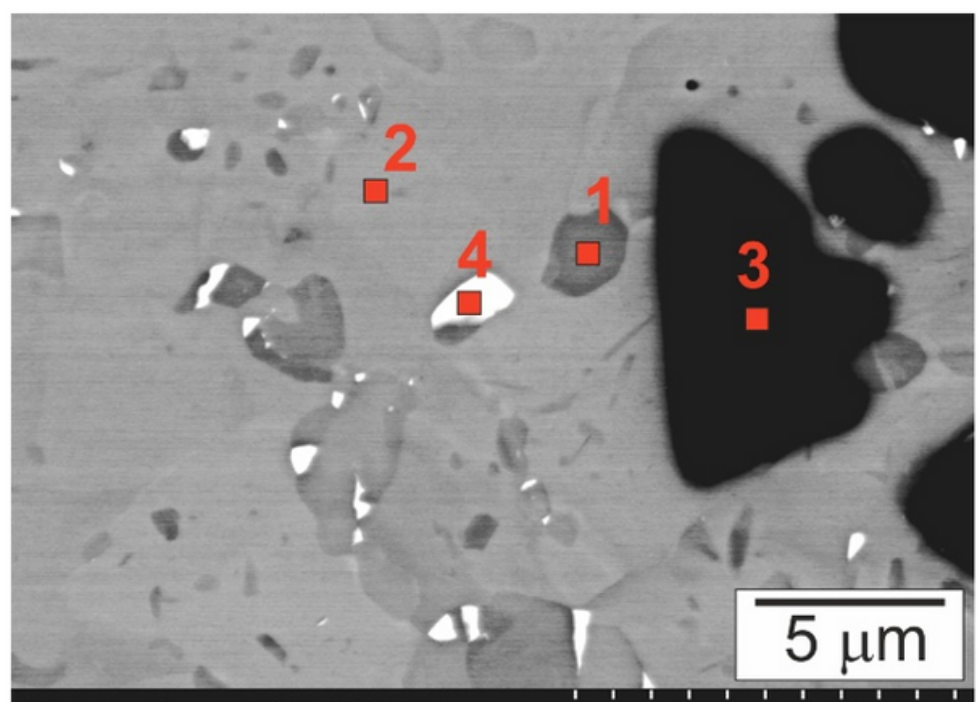

\begin{tabular}{|c|c|c|c|c|}
\hline Pt. & Cu-K & Sn-L & Sb-L & Pb-M \\
\hline 1 & 0.22 & 55.42 & 43.52 & 0.84 \\
\hline 2 & 0.20 & 98.20 & 1.48 & 0.12 \\
\hline 3 & 38.94 & 59.48 & 1.58 & - \\
\hline 4 & 0.08 & 55.39 & 0.86 & 43.68 \\
\hline
\end{tabular}

\section{Figure 4}

Microstructure of B89 alloy after FSP modification with speed of 280 RPM and results of spot analysis of chemical composition, wt\%; SEM

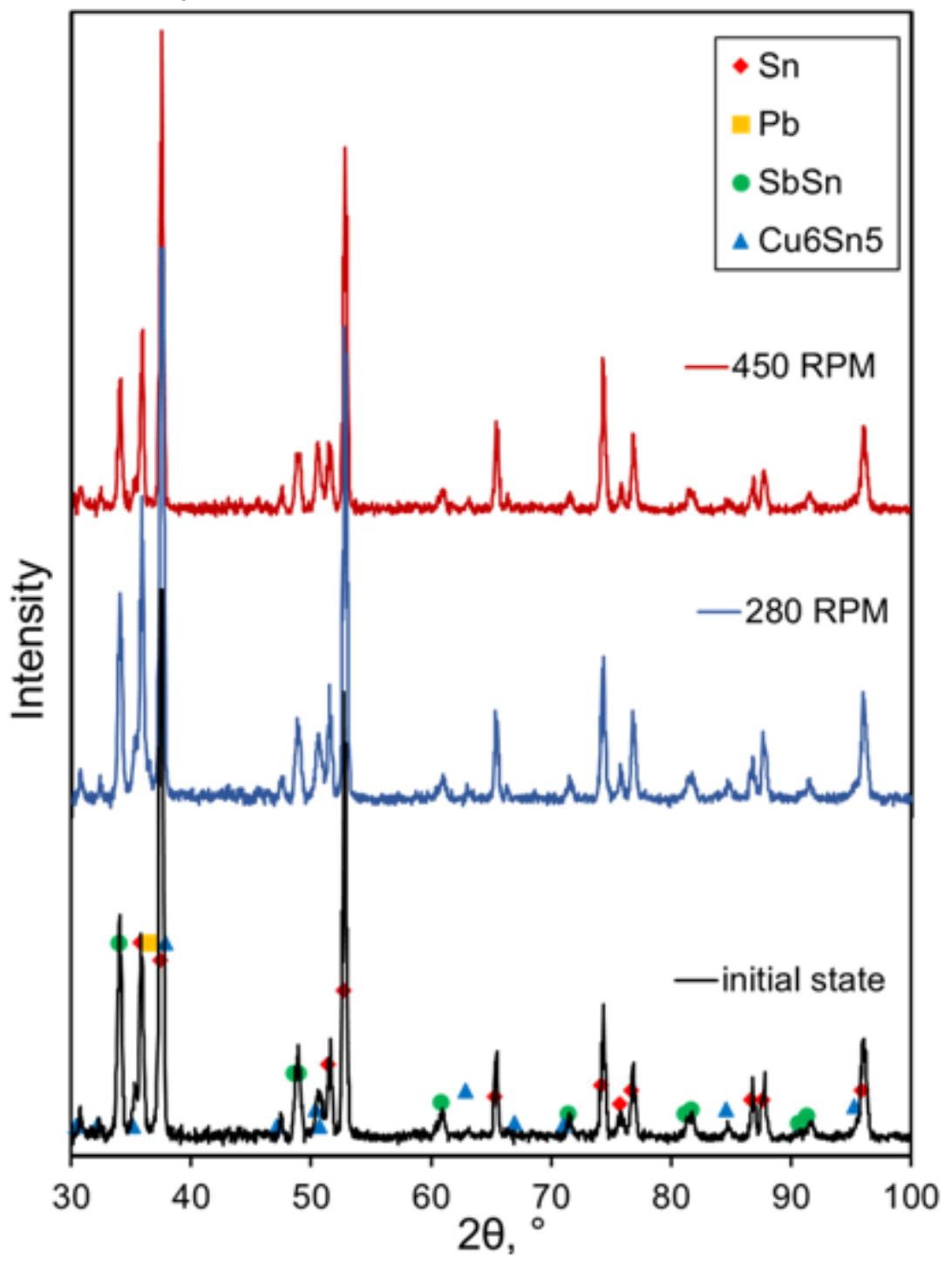




\section{Figure 5}

X-ray diffraction pattern of SnSbCu alloy for initial material and after FSP modification
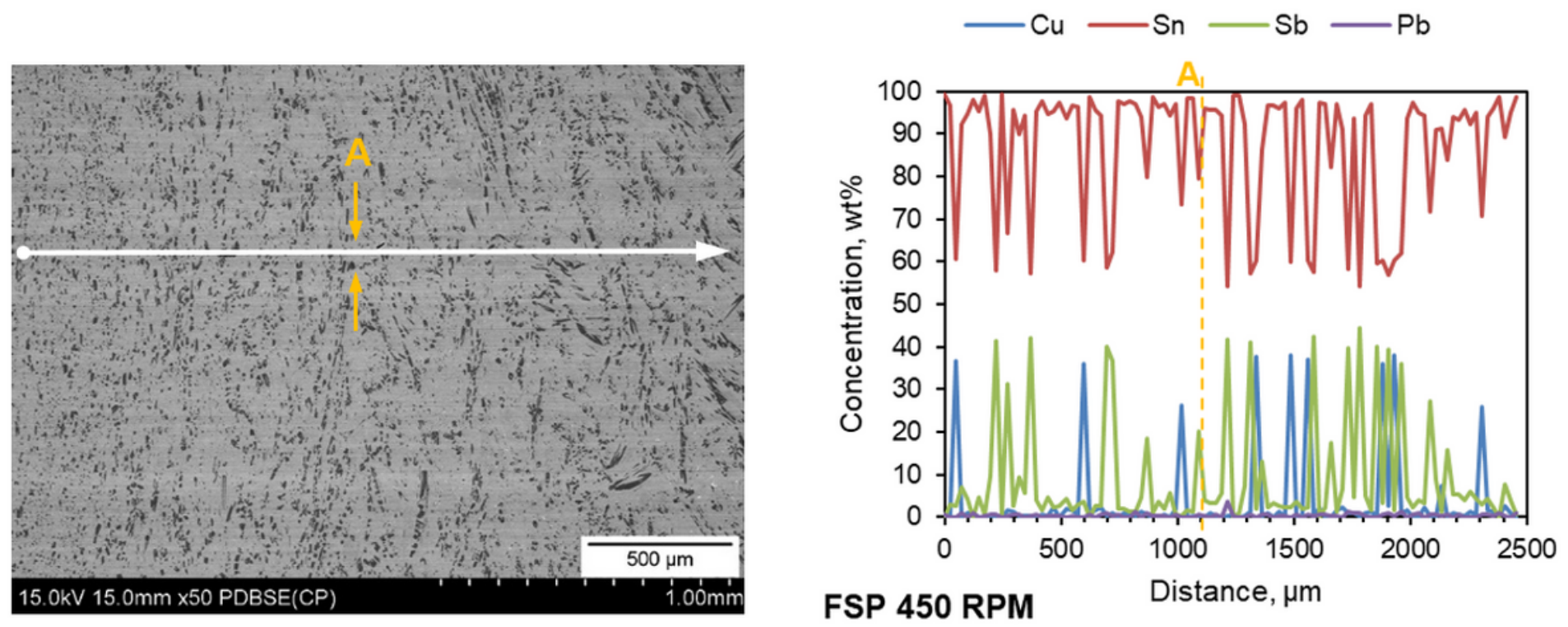

Figure 6

Microstructure of alloy after FSP treatment (450 RPM) with visible transition from FSP zone towards base material on advancing side and results of linear chemical composition analysis; SEM

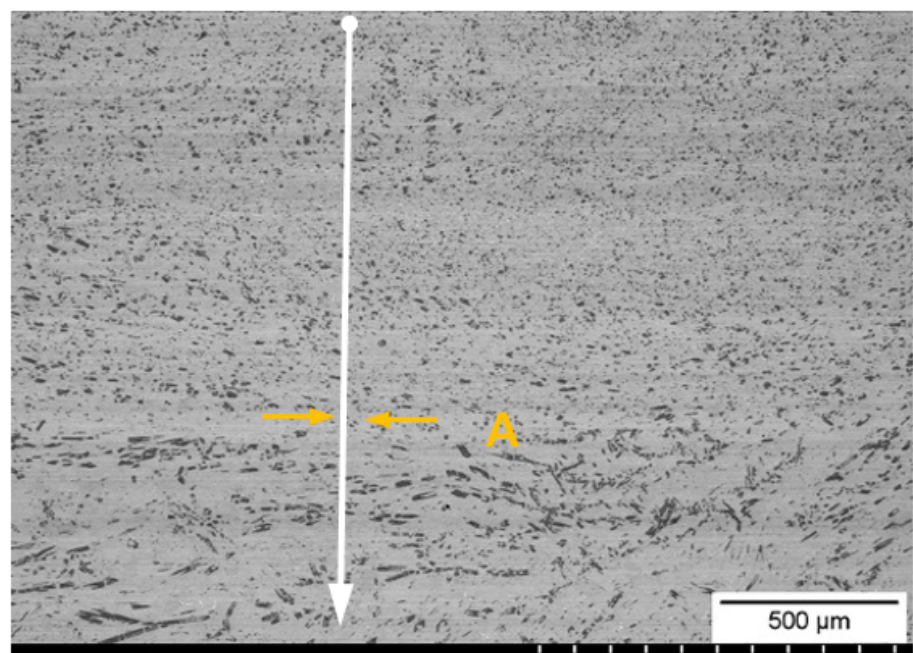

15.0kV 15.0mm x50 PDBSE(CP)

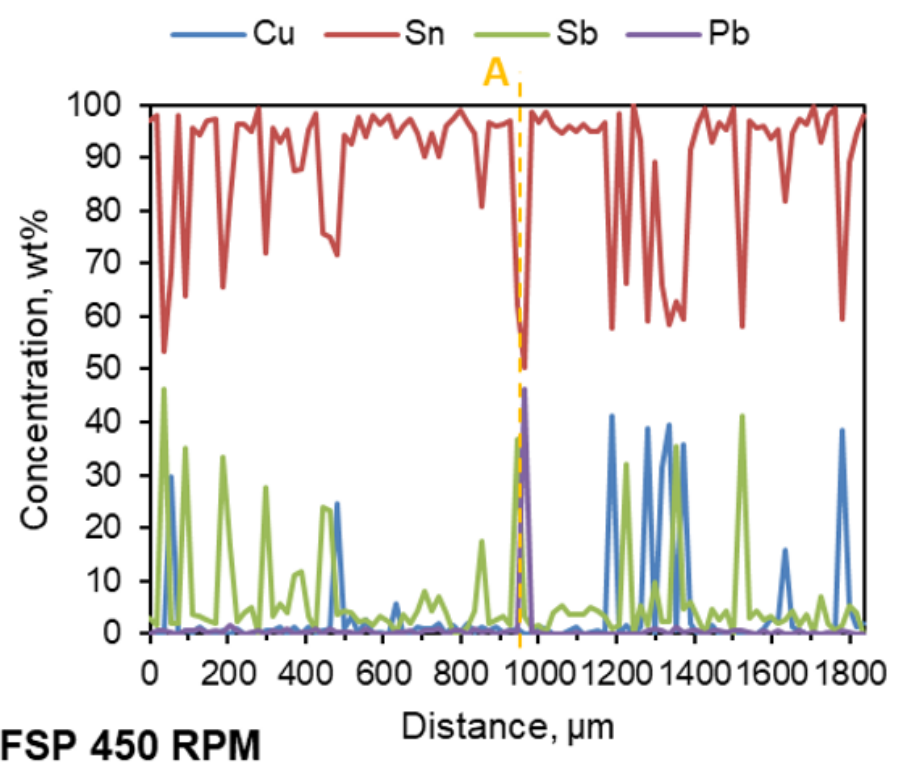

FSP 450 RPM

Figure 7

Microstructure of alloy after FSP treatment (450 RPM) with visible transition from area of lower FSP zone towards base material and results of linear chemical composition analysis; SEM 

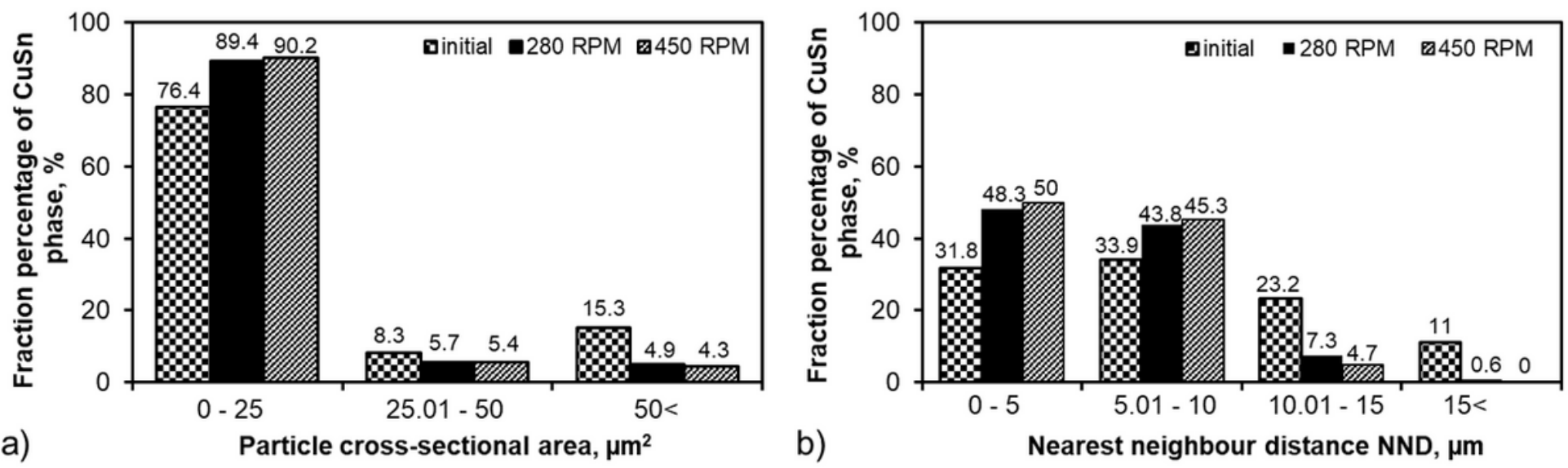

b)

Nearest neighbour distance NND, $\mu \mathrm{m}$

\section{Figure 8}

Results of statistical analysis of Cu6Sn5 precipitates depending on FSP conditions: a) precipitate size histogram, b) NND histogram; results are related to alloy after casting

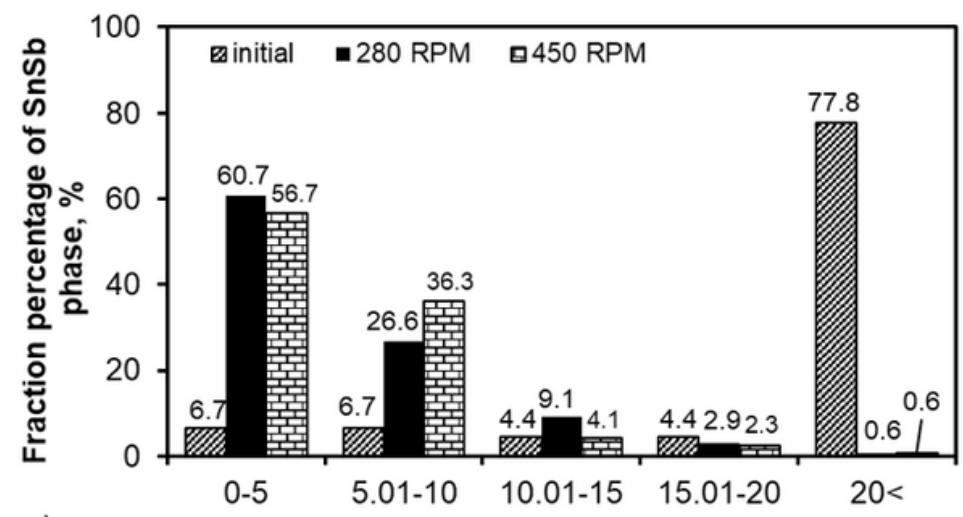

a)

Particle cross-sectional area, $\mu \mathrm{m}^{2}$

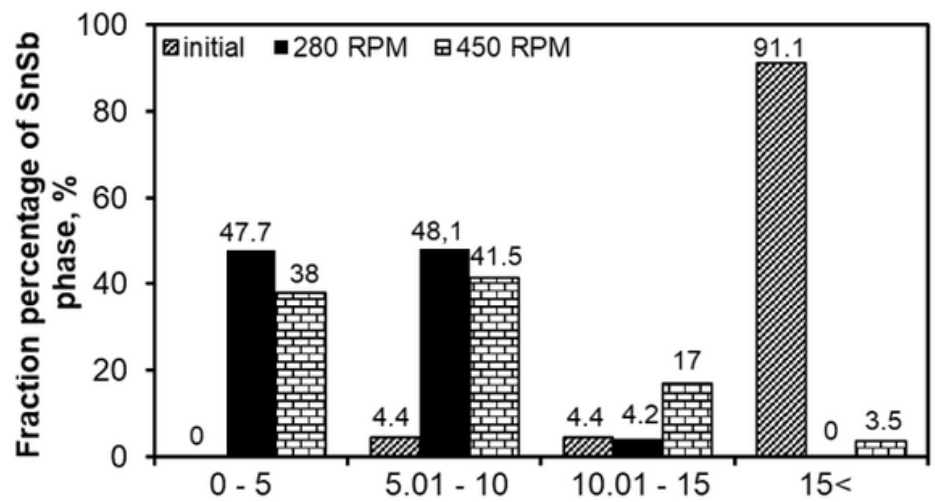

b) nearest neighbour distance NND, $\mu \mathrm{m}$

\section{Figure 9}

Results of statistical analysis of SnSb precipitates depending on FSP conditions: a) precipitate size histogram, b) NND histogram; results are related to alloy after casting 


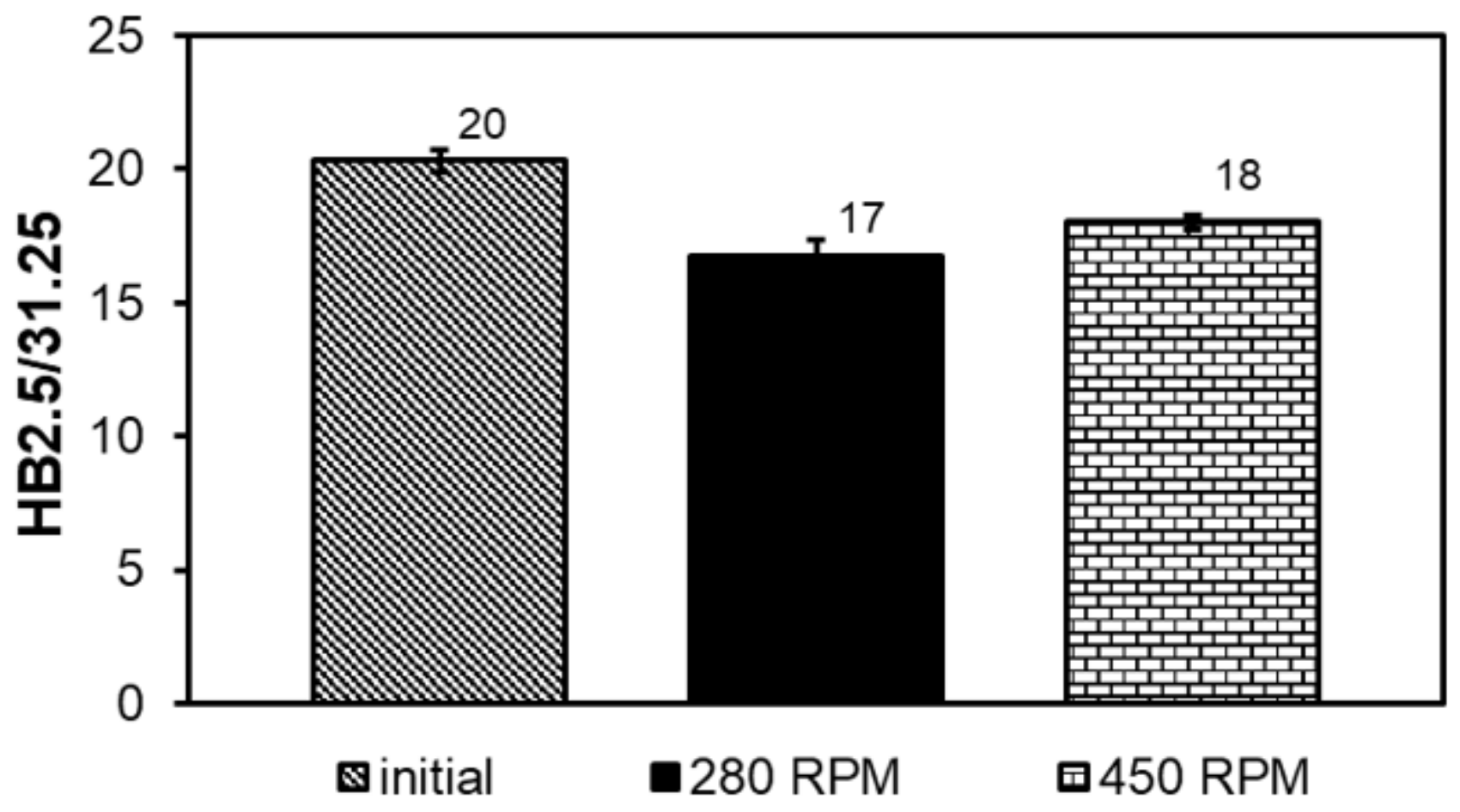

Figure 10

Comparison of SnSbCu alloy hardness before and after FSP modification

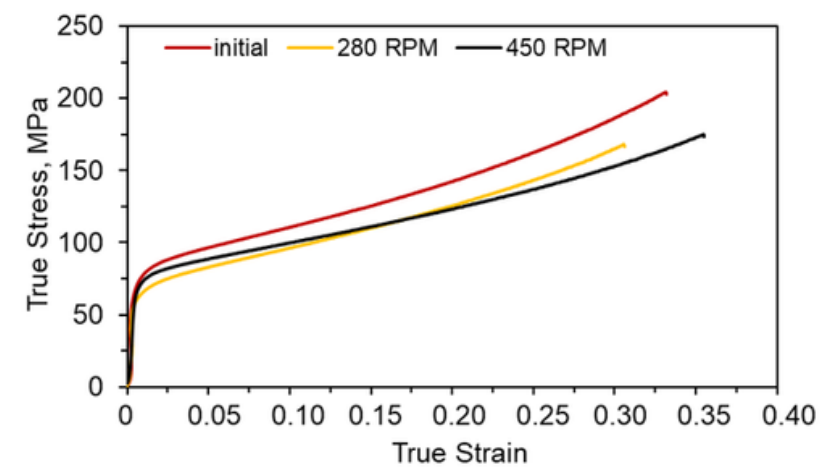

\begin{tabular}{|c|c|c|}
\hline Variant & $\boldsymbol{\sigma , M P a} a t \boldsymbol{\varepsilon}=\mathbf{0 . 1}$ & $\boldsymbol{\sigma , M P a} a t \boldsymbol{\varepsilon}=\mathbf{0 . 3}$ \\
\hline initial & 111 & 187 \\
\hline $280 \mathrm{RPM}$ & 96 & 165 \\
\hline $450 \mathrm{RPM}$ & 100 & 153 \\
\hline
\end{tabular}

Figure 11

Compression characteristics for SnSbCu alloy before modification and after FSP treatment with rotational speeds of 280 RPM and 450 RPM; table contains summary of stress values 

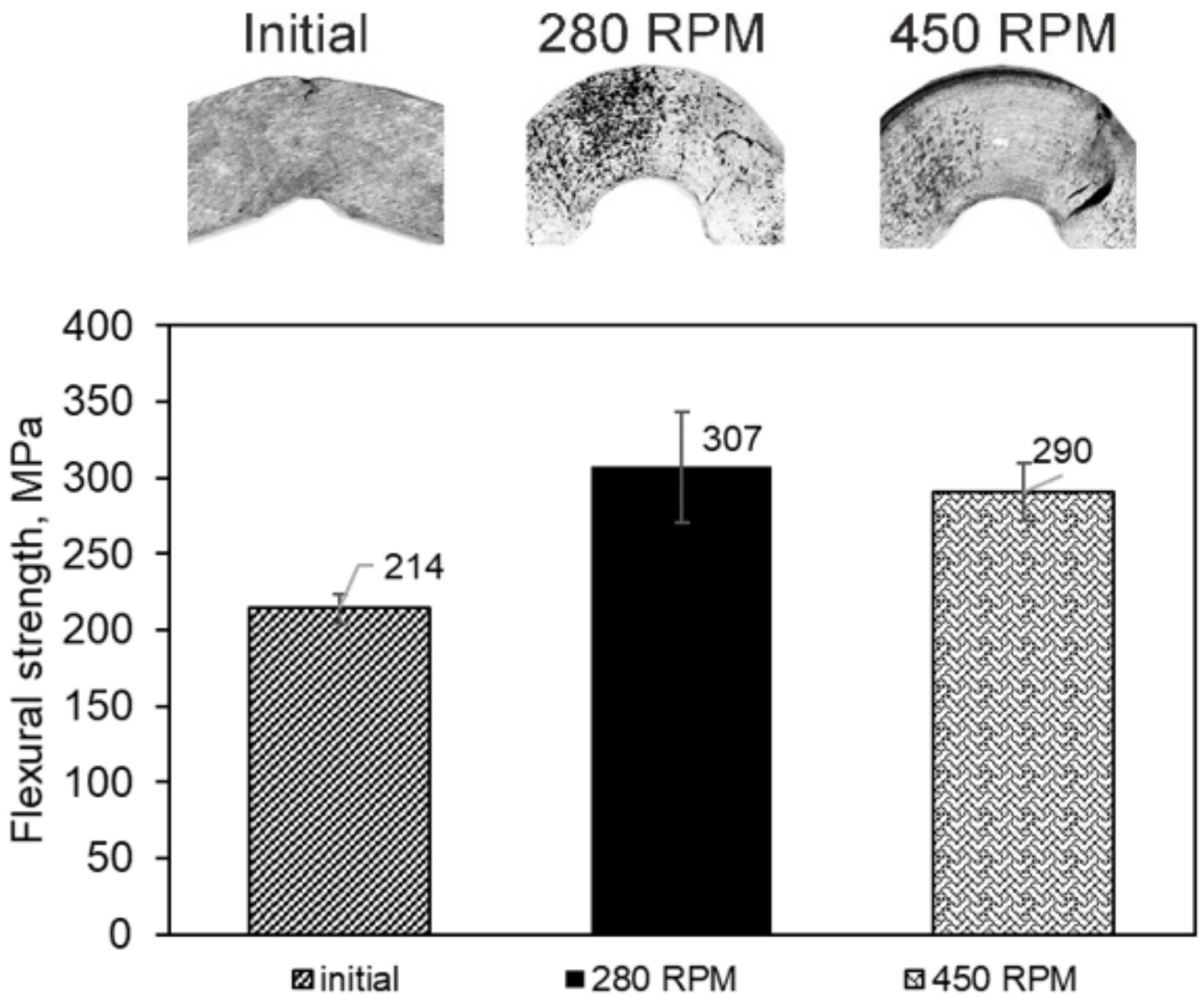

Figure 12

Flexural strength of SnSbCu alloy before modification and after FSP treatment and photos of samples after bending - side view with visible fracture area
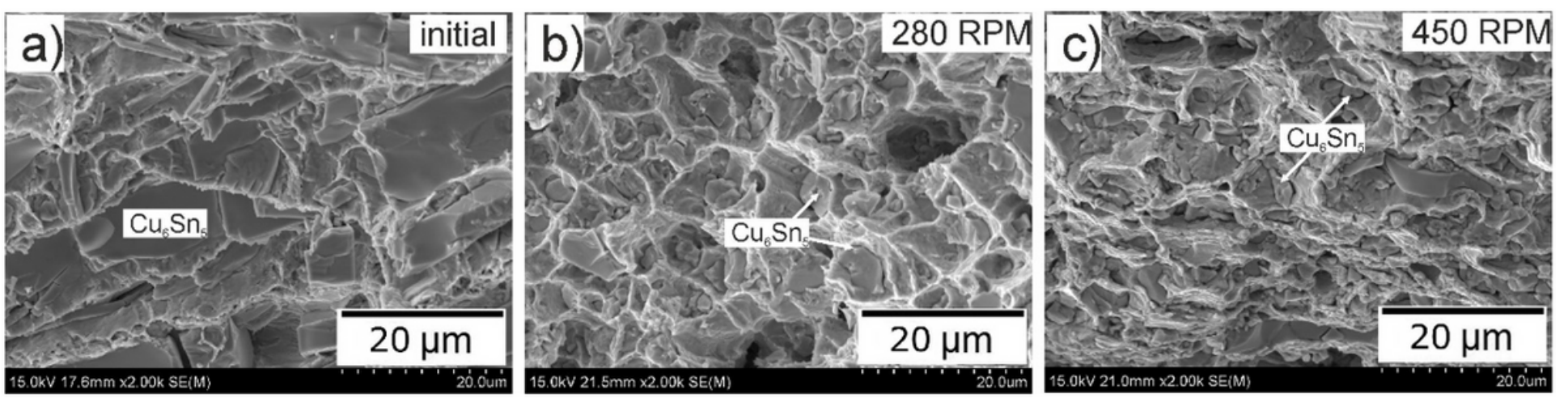

Figure 13

Fractures after three-point flexural test; a) initial material, b, c) after FSP modification; SEM 